\title{
MÁS ALLÁ DEL LAWFARE: AVATARES DE LA JUDICIALIZACIÓN DE LAS POLÍTICAS PÚBLICAS Y LOS CONFLICTOS SOCIALES EN ARGENTINA Y AMÉRICA LATINA
}

\section{BEYOND LAWFARE: SYMBOLS OF THE JUDICIALIZATION OF PUBLIC POLICIES AND SOCIAL CONFLICTS IN ARGENTINA AND LATIN AMERICA}

Andrés Scharager ${ }^{1}$

\section{RESUMEN}

El presente artículo se aboca a examinar sociológicamente el fenómeno de la judicialización, partiendo de un punto de vista multidimensional y haciendo foco en su productividad -esto es, sus efectos estructurantes y de largo alcance sobre el orden social y político-. En base al caso argentino, pero recuperando asimismo experiencias latinoamericanas, se desarrolla una metodología cualitativa de revisión de literatura por medio de la cual se procuran identificar los modos en que el problema en cuestión ha sido caracterizado y las facetas en las que ha sido categorizado. En esta clave, el trabajo se estructura en torno a tres ejes de análisis: el reposicionamiento del derecho y el Poder Judicial desde la vuelta a la democracia, el desplazamiento de los conflictos a los tribunales, y el auge del activismo judicial. Por último, se propone un conjunto de recaudos metodológicos y conceptuales para llevar a cabo una sociología de la judicialización.

Palabras clave: judicialización, conflicto social, políticas públicas, activismo judicial, derecho

\section{ABSTRACT}

This article seeks to sociologically examine the phenomena of judicialization, by standing on a multidimensional point of view and focusing on its productivity -that is, its structuring and longrange effects on the social and political order-. By focusing on the Argentinian case and recovering Latin American experiences, we shall undertake a qualitative methodology of literature review through which we will identify the ways in which this issue has been characterized and the

\footnotetext{
${ }^{1}$ Licenciado en Sociología (Universidad de Buenos Aires), Magíster en Antropología Social (Universidad Nacional de San Martín) y Doctor en Ciencias Sociales (Universidad de Buenos Aires) y Geografía (Université de Tours). Docente de la Carrera de Sociología de la Universidad de Buenos Aires y becario posdoctoral del Consejo Nacional de Investigaciones Científicas y Técnicas (CONICET) en el Instituto de Altos Estudios Sociales de la Universidad Nacional de San Martín (IDAES-UNSAM). ORCID Id: http://orcid.org/0000-0001-82176496 E-mail: andres.scharager@gmail.com
} 
dimensions in which it has been categorized. Thus, this paper is structured in three parts: the repositioning of law and the Judiciary since the beginning of the democratic period, the displacement of conflicts towards courts and the rise of judicial activism. Lastly, we will propose a series of methodological and conceptual forethoughts in order to carry out a sociology of judicialization.

Keywords: judicialization, social conflicts, public policies, judicial activism, law

\section{INTRODUCCIÓN}

Las últimas décadas han mostrado un renovado protagonismo del derecho y la justicia en la agenda pública argentina y latinoamericana. No sólo jueces, fiscales o los propios tribunales supremos han dado señales de una creciente capacidad de influencia en el devenir de conflictos que antes parecían reservados a canales extrajurídicos, sino que diversas organizaciones no gubernamentales, movimientos sociales, grupos empresariales e instituciones estatales han expresado una disposición cada vez mayor a recurrir a estas vías para vehiculizar sus demandas y hacer valer sus intereses.

Por un lado, cuantiosas protestas populares que en el pasado se hubieran impuesto gracias a la mediación de partidos políticos o a través de la acción directa se vieron trasladadas a los tribunales. Trátese de reclamos por aumentos de precios en el transporte público o el desalojo de asentamientos informales, abundan -y son cada vez mayores- los casos que han hallado cauce en la justicia. Para actores tales como sindicatos, asambleas ambientales, organizaciones vecinales o asociaciones de consumidores, la canalización de los conflictos a través del litigio se ha vuelto una opción notoria entre sus repertorios de acción.

Por otro lado, numerosas iniciativas de gobierno y disputas empresariales han estado signadas por la intervención judicial. Desde leyes bloqueadas por recursos de amparo hasta obras públicas obstruidas por medidas cautelares, las relaciones entre los actores políticos y económicos del país se han visto cada vez más intersectadas con las reglas, dinámicas y potestades de la justicia. Así, algunas de las principales medidas gubernamentales -como la regulación de los medios de comunicación o reformas en el sistema previsional- se desplazaron hacia el terreno del Poder Judicial. 
Según Arrimada (2017), "la judicialización de la política llegó para quedarse", y las investigaciones judiciales han sido instrumentalizadas para tomar decisiones de carácter netamente político y discrecional, pues han hecho del expediente un "arma" y de la justicia la continuación de la política por otros medios. Señala así que los actores políticos tienden a hallar en la judicialización una oportunidad para degradar el capital político de los adversarios, clausurar debates, dilatar la resolución de conflictos, forzar negociaciones y legitimar u ocultar decisiones políticas.

Los jueces, sin embargo, no se han limitado a ser meros receptores pasivos de esta nueva generación de demandas, sino que han mostrado una sustancial predisposición a involucrarse en la vida pública por medio de sentencias que sembraron controversias respecto de la extensión de los dominios de lo judicial vis à vis la política. Fuera por el pedido de detención de funcionarios gubernamentales o el bloqueo de incrementos exponenciales en las tarifas de servicios públicos, los magistrados han sido acusados de pretender alcanzar objetivos políticos por medio de interpretaciones extremas del derecho. Pero acaso el denominado lawfare (o "guerra jurídica") llevado a cabo contra líderes del "ciclo progresista" (KATZ, 2017) de América Latina sea el ejemplo más difundido de las nuevas inclinaciones políticas de la justicia. Casos como la deposición de Manuel Zelaya (Honduras), el encarcelamiento de Lula Da Silva (Brasil) y los procesamientos a Cristina Fernández de Kirchner (Argentina) han dado cuenta de que el lugar crecientemente preponderante del Poder Judicial en la definición de las pugnas políticas es un fenómeno de carácter regional.

En este marco, diversos magistrados han sido acusados de no ajustarse a las leyes vigentes y de crear inéditos antecedentes en la jurisprudencia. En numerosas ocasiones, sus argumentos, procedimientos y resoluciones generaron acalorados debates entre constitucionalistas, dirigentes políticos y en la opinión pública. Aunque hayan apelado, como de rigor, a la confrontación de pruebas con corpus legales para fundamentar sus sentencias, numerosos abogados y juristas han afirmado que sus actos han escapado a las reglas del campo del derecho.

En efecto, podría sostenerse que las mismas han reposado sobre un universo intrínsecamente lógico, que los juicios de valor se hallaron subsumidos al raciocinio y procedimientos legales y que, por ende, el Poder Judicial apenas se ha limitado a resguardar el orden jurídico y a responder a las denuncias conforme al derecho público. No obstante, como señala Abdo Ferez (2013), los jueces han tendido a adquirir un protagonismo y visibilidad pública cada vez mayores, habiéndose hecho de un gran poder decisorio respecto del derrotero de numerosos 
conflictos. Así -siguiendo a Santos (2009)-, su rol proclive a la intervención en coyunturas políticas se ha traducido en enfrentamientos con dirigentes, partidos y los poderes ejecutivos.

En definitiva, la judicialización es un fenómeno polifacético que ha transformado las relaciones entre actores sociales en pugna, generando impactos diversos en el debate público, en las agendas gubernamentales y en el desarrollo de la conflictividad.

Entendido también como "democracia judicial" (KALUSZYNSKI, 2006), "juristocracia" (HIRSCHL, 2004) y "giro judicial" (MARTIN, 2011), el tema ha sido objeto de producción académica en diversos rincones del globo, desde Asia hasta Estados Unidos (TATE, 1994; EDELMAN, 1994; HE, 2013; SHAPIRO, 1994). Pero los estudios han sido especialmente prolíficos en América Latina, donde han primado distintos tipos de preocupaciones.

Por un lado, se halla un grupo de investigaciones que, influenciadas por tradiciones de la filosofía y la ciencia política, retratan a la justicia como el "poder más débil, el que [debe] ser protegido de la voracidad de los restantes" (ABDO FEREZ, 2013: 55). En última instancia, sostienen una concepción de la justicia como poder "contramayoritario" que se resguardaría del vaivén de los humores sociales y garantizaría la estabilidad del régimen político (NOSETTO, 2014). Según Kapiszewski y Taylor (2008), este tipo de trabajos tienden a preguntarse por el tipo de control que ejercen las cortes sobre los poderes ejecutivos y legislativos, las consecuencias de su intervención sobre la consolidación democrática y los posibles riesgos para el sistema de división de poderes. Anclados en una preocupación por el derrotero político-institucional de las naciones latinoamericanas, estos estudios atravesaron al conjunto de la región durante el auge del período posneoliberal, hallándoselos en países políticamente tan disímiles como Brasil (SANTISO, 2004), México (FINKEL, 2005), Ecuador (CONAGHAN, 2012), Chile (HILBINK, 2003) y Venezuela (PÉREZ PERDOMO, 2005).

Otro grupo de trabajos latinoamericanos se ha caracterizado por una preocupación en torno a los efectos de largo alcance de la judicialización sobre la vida social (AZUELA, 2014). En lugar de valorar estos fenómenos de acuerdo a su impacto sobre la división de poderes y el funcionamiento de la democracia, estos escritos exploran las transformaciones que acarrea la creciente influencia de la justicia y el derecho en la tramitación de demandas. Algunos de ellos se focalizan en las potencialidades y límites del litigio a la hora de garantizar derechos (GARGARELLA, 2006; HILBINK, 2008), trátese de los referidos al acceso a medicamentos (BIEHL et al., 2012), a la salud sexual y reproductiva (PEÑAS DEFAGO Y MORÁN FAÚNDES, 2014) o a la vivienda (KONZEN, 2014). Otros 
tantos, por su parte, indagan en los efectos de la constitucionalización de los derechos sociales en relación a su exigibilidad, es decir, la existencia de herramientas legales para el reclamo de su cumplimiento (BRINKS Y GAURI, 2014).

En este sentido, en la Argentina se han acrecentado los estudios que abarcaron problemáticas como la judicialización de los derechos sociales (ARCIDIÁCONO Y GAMALLO, 2014), de la protesta social (AXAT et al., 2003), de las reivindicaciones en materia de género (CARDINAUX et al., 2012), de los conflictos ambientales (MERLINSKY, 2013), de las luchas por la urbanización de villas (DELAMATA, 2016) y de las disputas por los usos del suelo urbano (AZUELA Y COSACOV, 2013). Los ejes de análisis han variado desde el rol de los jueces y las transformaciones institucionales generadas por sus sentencias hasta los usos del derecho por parte de los actores y sus modos de movilización. El denominador común, a fin de cuentas, ha sido una preocupación por las tensiones inherentes al tránsito de los conflictos de un lado al otro de la frontera político-judicial.

Centrándose en el caso argentino pero recuperando a su vez experiencias latinoamericanas, este artículo se propone analizar los orígenes y los efectos de la judicialización de los procesos políticos y los conflictos sociales. Se procurará, a lo largo de este recorrido, atender a su carácter multidimensional y colocar el eje en su productividad (MELÉ, 2011; AZUELA, 2014), esto es, sus efectos duraderos y estructurantes sobre el orden político y las relaciones entre los actores. Para ello, en primer lugar se realizará una genealogía del fenómeno, revisándose algunos de los factores jurídicos, políticos y culturales que condujeron al reposicionamiento del derecho y el Poder Judicial en la Argentina reciente. En segundo lugar, se examinarán los modos en que distintos tipos de conflictos tienden a trasladarse al terreno del litigio, resaltándose sus implicancias para los actores y las demandas en juego. En tercer lugar, se colocará el foco en la judicialización desde el punto de vista de los operadores jurídicos, tanto jueces que se involucran en la formulación de políticas como defensores públicos que se abocan a la protección de población afectada por medidas gubernamentales. Por último, se propondrá un conjunto de recaudos metodológicos y puntos de partida conceptuales para llevar a cabo una sociología de la judicialización de los procesos políticos y los conflictos sociales en América Latina. 


\section{EL REPOSICIONAMIENTO DEL DERECHO Y EL PODER JUDICIAL EN LA ARGENTINA DEMOCRÁTICA}

La transición democrática constituye un momento insoslayable para periodizar y explicar la expansión del fenómeno de la judicialización en la Argentina. Desde el primer golpe de Estado ocurrido en 1930 hasta el fin de la última dictadura en 1983, el país había experimentado décadas políticamente turbulentas en las cuales las interrupciones del orden legal, la restricción de la democracia a raíz de la proscripción del peronismo y la violencia política se habían vuelto moneda corriente. La caída del régimen militar, en ese sentido, fungió como parteaguas que dio inicio a una nueva etapa signada por el repliegue político de las Fuerzas Armadas, la estabilización del sistema de partidos y la vigencia de las garantías constitucionales.

En particular, el juicio a las juntas militares llevado a cabo tras la caída del régimen tiende a ser identificado como determinante para el inicio de un reposicionamiento político y simbólico del Poder Judicial y del Estado de derecho en su conjunto (SMULOVITZ, 2008; NOSETTO, 2014). Por un lado, implicó que los tribunales en los que se enjuiciaba a los responsables de la dictadura militar se colocaran en el centro de la agenda pública, pues del resultado de esos juicios dependería el devenir del cambio de régimen en aquellos turbulentos primeros momentos de la transición. Por ende, la experiencia de los juicios facilitó también un proceso de autoafirmación de los jueces, que estaban teniendo una centralidad sin precedentes en temas políticos altamente sensibles (DOMINGO, 2004). Por otro lado, los juicios operaron como puntapié hacia un aumento de las expectativas depositadas en las instituciones, entendidas como capaces de resolver los problemas sociales. Este viraje cobró especial relevancia luego de años en que el autoritarismo, la violencia y la censura tendían a ser la respuesta habitual a la conflictividad.

El protagonismo de los movimientos de derechos humanos en aquellos años de reinstauración democrática, así como el de grupos de abogados que durante la dictadura batallaban legalmente contra la desaparición forzada de personas mediante la presentación de recursos de amparo, también reposicionó socialmente a la justicia (DOMINGO, 2004). Si a mediados del siglo XX la "cultura de derechos" era más bien estatalista, pues se encarnaba en las conquistas alcanzadas bajo el liderazgo de Perón, ésta se transformaría en la transición de la década de 1980 de la mano de las organizaciones de derechos humanos, que interpelaban a la sociedad con el principio del "derecho a tener derechos" (MARTIN, 2011: 368). En este período, apuntan algunos autores, se reconoció el valor de los derechos como reguladores sociales (NOSETTO, 2014), las propias 
percepciones acerca de la ley se vieron transformadas, y el sistema judicial se visualizó como un espacio para la canalización de los conflictos (SMULOVITZ, 2008).

A estos elementos que dan cuenta de una nueva "cultura legal" (DOMINGO, 2004), consistente en el reconocimiento del sistema judicial y la ley como instrumentos ordenadores del nuevo Estado de derecho, se agregan factores internacionales. El lenguaje y el discurso en torno a los derechos humanos, cada vez más universalmente aceptados (ver recuadro), impactaron no sólo en el plano de las reivindicaciones e imaginarios sociales, sino en la emergencia de marcos legales y tratados que se difundieron transnacionalmente en un proceso de "globalización legal" (SIEDER, SCHJOLDEN Y ANGELL, 2008) y adquirieron estatus jurídico a nivel local con su incorporación a la Constitución Nacional en 1994.

\section{$\underline{\text { La expansión del neoconstitucionalismo }}$}

En enfoque de los "derechos fundamentales", conocido también como "neoconstitucionalista", consiste en un discurso jurídico que, expandido en América Latina en las últimas décadas, reivindica la importancia de la justicia como reguladora de los conflictos que llegan a los tribunales y subraya su aptitud para impulsar cambios acordes a los proyectos y derechos plasmados en las nuevas leyes y constituciones. Este enfoque coloca a los derechos inherentes a las personas -esto es, los derechos humanos- en el centro del análisis, convirtiéndose en un fundamento argumental explícito de la reflexión jurídica en su conjunto (CARBONELL, 2007, citado en AZUELA, 2014: 11).

Diferenciada del constitucionalismo que sucedió a las revoluciones burguesas de fines del siglo XVIII, esta corriente puede ser entendida como concepción acerca de la realidad jurídica e incluso como postura ideológica acerca de la función de los jueces en una democracia constitucional (SANTIAGO, 2008: 4). Surgido tras la conmoción política y moral de la Segunda Guerra Mundial, este enfoque trasladó al plano jurídico el avance del paradigma de los derechos humanos, que por medio de tratados y convenciones internacionales estaba en vías de institucionalizar una nueva moral y un inédito piso de garantías individuales y sociales. Estos preceptos fueron incorporados al entramado jurídico de algunos países europeos en reformas constitucionales tempranas (Italia, en 1947; Alemania, en 1949), mientras que otros lo hicieron luego de tardías aperturas democráticas (Portugal, en 1976; España, en 1978). En América Latina, por su parte, este proceso también tuvo su puntapié en la caída de las dictaduras y el fin 
del período autoritario: modificaron su Carta Magna países como Brasil y Chile (1989), Colombia (1991), Paraguay (1992), Bolivia y Perú (1993), y Argentina, Nicaragua y Guatemala (1994).

La transformación neoconstitucional de los marcos legales en diversas regiones del globo fue entonces la expresión en el plano normativo de la creciente centralidad de los derechos humanos en la vida pública e institucional (SANTIAGO, 2008). Pero además de tomar la forma de cambios legislativos y volverse valores que extendían su influjo a las relaciones sociales mismas, comenzaron a impregnar el ordenamiento político-jurídico del Estado por medio de un detalle minucioso de los derechos constitucionales de las personas y una consagración de las garantías que los hacen efectivos.

Puntualmente, el proceso constituyente implicó la incorporación a la Carta Magna de nuevos derechos denominados "de segunda generación" y de "tercera generación", muchos de los cuales se habían plasmado en la Declaración Universal de los Derechos Humanos de 1948 y en el Pacto Internacional de Derechos Económicos, Sociales y Culturales de $1966^{2}$. Pero además de generar herramientas para la lucha contra la discriminación, jerarquizar el derecho a la vivienda y otorgar protección a pueblos originarios, a consumidores y al medioambiente, la reforma de la Constitución también reconoció herramientas como el amparo, la cual legitimó la apelación a la justicia tanto de parte de ciudadanos afectados como de asociaciones civiles y de nuevas entidades de defensa de derechos destinadas a "[defender] la legalidad de los intereses generales de la sociedad" (Art. 120, Constitución Nacional).

En efecto, tanto en el caso argentino como en toda la generación de reformas constitucionales en América Latina de aquella época se incrementó el tipo y la cantidad de actores legitimados para presentar demandas, y se estipuló la conformación de organismos encargados de litigar en nombre del interés público, tales como la "Procuraduría Federal de los Derechos del Ciudadano" en Brasil, la "Procuraduría para la Defensa de los Derechos Humanos" en El Salvador y el "Defensor de los Habitantes" en Costa Rica. Entidades como estas ampliaron las vías de acceso a las cortes y junto con organismos no gubernamentales se volvieron en un vehículo para la

\footnotetext{
${ }^{2}$ Mientras que los derechos de primera generación refieren a los derechos civiles y políticos (la libertad de expresión y de culto, el sufragio, la libre circulación, reunión y manifestación, la presunción de inocencia, entre otros), los de segunda y tercera generación tienden a hacer alusión a los derechos económicos, sociales y culturales. Estos incluyen el derecho al trabajo, a la asociación sindical, a la salud, a la educación, a la participación en la vida cultural, al agua, a la vivienda, a la alimentación y al ambiente.
} 
tramitación judicial de diversas demandas sociales. Particularmente, estas plataformas de apoyo (SMULOVITZ, 2008) o redes de patrocinio (ARCIDIÁCONO y GAMALLO, 2014) se han abocado a la defensa de población vulnerable afectada por políticas estatales, adoptando como tarea garantizar el acceso a la justicia por medio del trabajo político-territorial (AUTOR, 2019). Más aún, estas redes han conformado una "comunidad legal garantista" que a la par de jueces y abogados-académicos "[ha] venido potenciando y expandiendo el discurso jurídico en asuntos tradicionalmente abordados por el discurso político, mediante su participación en debates públicos, demandas judiciales, sentencias, etc." (DELAMATA, 2013: 151) . $^{3}$

En diálogo con la sociología de la acción colectiva, podría afirmarse que las redes de patrocinio y la propia reforma constitucional apuntalaron la judicialización al otorgar jerarquía a un vasto conjunto de derechos y crear novedosas herramientas para garantizarlos (NOSETTO, 2004). Es decir que los cambios generados en la estructura de oportunidades sociales y legales (SMULOVITZ, 2008; TILLY, 2008) se convirtieron en la condición de posibilidad para que diversos colectivos de actores concibieran la utilización de nuevas herramientas para dar curso a la conflictividad. Como señala Smulovitz (2008), las redes y organismos abocados al litigio de derechos facilitaron el acceso a las cortes y permitieron la persistencia de las acciones de demanda, especialmente por parte de actores sin habilidades profesionales, conocimientos técnicos, o incluso tiempo y capacidad de canalizar sus reclamos por otras vías.

Finalmente, algunos autores colocan a la crisis del Estado de bienestar surgida en la década de 1970 como factor explicativo del creciente traslado de los conflictos políticos y sociales a la esfera del litigio. Tanto Nosetto (2014) como Smulovitz (2008) sostienen que la retracción de este modelo y el ascenso del Estado neoliberal dieron lugar a una complejización de la estructura social y la aparición de nuevos movimientos, identidades y demandas que, al verse incapaces de ser satisfechas por un bienestarismo en retirada, encontraron su cauce por vía judicial. Podría afirmarse entonces que en el marco de esta crisis y de la transición democrática, tanto la expansión del "catálogo de derechos" (DELAMATA, 2013) como la creación de nuevas herramientas legales y la emergencia de actores que facilitan el acceso a la justicia, funcionaron "como pinzas" (NOSETTO, 2014) que condujeron a la tramitación judicial de asuntos que anteriormente se hallaban restringidos a la acción política.

\footnotetext{
${ }^{3}$ En la tercera sección se retomará la descripción de los organismos de defensa pública.
} 


\section{EL DESPLAZAMIENTO DE LOS CONFLICTOS A LOS TRIBUNALES: EFECTOS MATERIALES Y SIMBÓLICOS DE LA APELACIÓN A LA JUSTICIA}

Analizar la judicialización en sus múltiples aristas implica no circunscribir la política a su sentido más estricto, restringiéndola a términos partidarios o institucionalistas. La apelación a la justicia no sólo ha sido elección de políticos sino que, como resalta Smulovitz (2008), también ha sido preferida por actores desorganizados, pequeños o con objetivos precisos. Para ellos, las condiciones de acceso a los tribunales resultan menos exigentes que las que caracterizan a otras formas de intervención política, cuyo éxito suele depender de la capacidad de emprender acciones colectivas y dar cuenta de algún grado de generalidad de los reclamos. Para intervenir en la arena judicial, señala la autora, los actores no precisan demostrar la extensión de sus reivindicaciones, y por ende no deben de por sí diluir la particularidad de sus demandas. En su lugar, apenas se les exige la justificación de sus peticiones según reglas preexistentes y con argumentos razonables, y aunque esto no les garantiza resultados, sí reduce los requisitos que habilitan su acción. Por ende, "al enmarcar sus acciones en el lenguaje y la lógica del derecho, actores minoritarios pero con objetivos intensos consiguen sortear las dificultades que enfrenta la organización de acciones colectivas en la arena política" (2008: 289). Basta con remitirse a casos recientes como resistencias vecinales a la construcción de aeropuertos o edificios en barrios residenciales para tomar nota de estos modos de apelación a la justicia.

A fines de 2017, en la localidad bonaerense de El Palomar comenzó la remodelación de una base aérea militar con el fin de adaptarla a usos comerciales, en particular para las operaciones de una nueva aerolínea de "bajo costo" (o low cost). Una vez que iniciaron las obras, grupos de vecinos que habitaban en las proximidades comenzaron a movilizarse, distribuir panfletos y realizar campañas públicas alertando contra los perjuicios que traería el uso intensivo del predio: contaminación sonora y ambiental, afectación a las escuelas circundantes, riesgo para espacios naturales protegidos, alteración de la tranquilidad de la zona y daño a un Sitio de Memoria desde donde operaban los "vuelos de la muerte" durante la dictadura militar ${ }^{4}$. En busca de frenar esta obra -principal emblema de la decisión gubernamental de implementar la libre competencia (o política de "cielos abiertos") en el transporte aéreo-, los vecinos presentaron un recurso de amparo

\footnotetext{
4 Se denomina "vuelos de la muerte" a una práctica llevada a cabo por las Fuerzas Armadas durante la dictadura (1976-1983) consistente en el arrojo de personas detenidas-desaparecidas desde aviones hacia el río.
} 
reclamando su cese. Pocas semanas después, una jueza dio lugar al pedido exigiendo asimismo una evaluación de impacto ambiental y un informe de la Secretaría de Derechos Humanos.

Un segundo conflicto que amerita traerse a colación tuvo sus orígenes en 2006, cuando un grupo de vecinos de la ciudad de Buenos Aires, alertados por un alza exponencial en la edificación y un cambio en la fisionomía de las calles de su barrio, comenzaron a movilizarse denunciando la alteración de su estilo de vida, la falta de luz natural que generarían las sombras de las grandes torres, y el riesgo de la saturación del servicio eléctrico, de agua y de gas. Por medio de cortes de calle, cacerolazos y movilizaciones lograron instalar el conflicto en la agenda mediática, y a partir de la presentación de recursos de amparo obtuvieron resoluciones judiciales que ordenaron al Gobierno de la Ciudad la suspensión de nuevos permisos de edificación.

Siguiendo a Azuela y Cosacov (2013), puede argumentarse que, en este caso, la judicialización tuvo consecuencias significativas que excedieron a los efectos directos de las resoluciones de los jueces intervinientes. El fundamento con el cual se presentaron los amparos, que en su mayoría referían al peligro de que se generase un daño ambiental, condujeron a una "ambientalización" del conflicto: al redefinirse, éste tendió a desplazarse del eje de controversias por los "usos del suelo" y se comenzó a insertar en el amplio campo de luchas ambientales que estaba en auge en aquel entonces. Por eso, Azuela (2014) recuerda que deben tenerse tres precauciones al analizar un caso como éste. En primer lugar, que el hecho de que un conflicto se judicialice no implica que se convierta en su totalidad en procedimientos jurídicos; en segundo lugar, que al entrar al mundo del derecho aparecen relaciones de poder que son propias del campo jurídico y que pueden afectar el resultado del conflicto; $y$ finalmente, que su ingreso a dicho campo produce una redefinición del mismo, por lo cual también se transforma lo que está en disputa. Por ende, la inscripción de los conflictos en el plano judicial supone un desplazamiento hacia otras arenas y a la vez una mutación de las reglas con las que éstos se dirimen.

El vertiginoso ascenso en la última década de las luchas por los derechos LGBT constituye otro ejemplo de cómo la conquista de reivindicaciones y la instalación de determinadas problemáticas sociales en la agenda pública ha sido facilitada por el traslado de las demandas a los tribunales. El caso de mayor resonancia fue la aprobación en el año 2010 de una ley que, tras extendidos debates parlamentarios, en los medios de comunicación y en la sociedad en general, habilitó el matrimonio entre personas del mismo sexo. Conocida como "Ley de Matrimonio Igualitario", esta iniciativa fue motorizada por organizaciones ligadas al movimiento LGBT que, 
además de apelar a movilizaciones y a la vía legislativa para instalar sus reclamos en la agenda pública, recurrieron paralelamente a la justicia a partir de 2007 de acuerdo a una estrategia políticojudicial planificada (FEDERACIÓN ARGENTINA LGBT, s/f). El tránsito de esta demanda por los tribunales constituyó un canal de presión que instaló el debate a nivel social e impulsó la discusión legislativa.

Puede traerse a colación un último caso que, contrariamente al argumento de Smulovitz (2008) expuesto anteriormente, muestra cómo los actores sociales en conflicto que han apelado a la justicia también han contado con una significativa capacidad de movilización y captación de atención pública. En 2003, un grupo de vecinos de la ciudad argentina de Gualeguaychú se anotició de que a escasos kilómetros, sobre la costa del Río Uruguay -que hace las veces de frontera con el país homónimo-, iniciaría la construcción de dos fábricas productoras de pasta de celulosa. Alertados por su carácter potencialmente contaminante, los habitantes de esta localidad reclamaron la suspensión de los proyectos por medio del bloqueo de un puente internacional, manifestaciones en la ciudad de Buenos Aires y en cumbres políticas regionales, e incluso a través del tejido de redes con asambleas ambientales de otras localidades ribereñas de su provincia que, en solidaridad, cortaron el resto de los accesos terrestres al país vecino. En paralelo a las protestas, la "Asamblea de Gualeguaychú" le exigió continuamente al gobierno argentino que elevase una demanda contra la República Oriental del Uruguay ante la Corte Internacional de Justicia por incumplimiento del tratado de uso compartido del río. En 2006, luego de años de escalada diplomática y de crecimiento del conflicto, el gobierno aceptó el pedido de los manifestantes y trasladó el conflicto a dicho tribunal, que dictó sentencia en 2010 reconociendo violaciones al Tratado del Río Uruguay pero descartando cualquier orden de desmantelamiento, que aparecía como la única solución viable para los asambleístas.

El ingreso de la justicia a este extenso y profundo conflicto -o bien el desplazamiento del conflicto hacia la justicia- permite extraer dos conclusiones relevantes a la luz de las discusiones hasta aquí planteadas. Por un lado, la demanda presentada ante el tribunal de La Haya abrió una ventana de cuatro años de espera que, lejos de llevar a una suspensión de las medidas de acción directa, las vio sostenerse e incluso radicalizarse. Como recuerda Abramovich (2005), las estrategias legales en ocasiones se ven acompañadas por el activismo y movilización de los protagonistas del conflicto, que buscan mantener la visibilidad de sus reclamos y dar cuenta -por vías extrajurídicasde aquello que está en juego en el expediente judicial. En otras palabras, la movilización legal y la movilización política no constituyen polos opuestos, sino que aquella puede ser entendida como 
parte de los repertorios de ésta (ARCIDIÁCONO Y GAMALLO, 2014: 44). Así, en el caso de Gualeguaychú, la justicia no apareció como una vía suplementaria a los métodos tradicionales de los movimientos sociales y los grupos de protesta, sino que los complementó.

Por otro lado, sin embargo, el dictado de sentencia por parte del tribunal internacional sí operó como punto de quiebre para el inicio del fin del conflicto. Luego de pronunciado el fallo, desgastes internos y presiones externas condujeron a que paulatinamente los asambleístas de Gualeguaychú comenzaran a desmovilizarse. Las esperanzas depositadas por los actores en la canalización judicial del diferendo, y por ende en la capacidad de las instituciones de la justicia en dar respuesta a una demanda popular cuando todas las otras vías parecían no estar dando los resultados esperados, da cuenta de cómo en paralelo a la judicialización de los conflictos puede evidenciarse una juridificación de las expectativas de los actores. En otras palabras, un conflicto se juridifica no sólo cuando éstos apelan a la justicia para dar curso a sus reivindicaciones, sino cuando se formulan horizontes y representaciones que se adecúan a las reglas de lo posible y lo esperable en el mundo jurídico.

Son entonces numerosos los grupos de protesta que apelan a los tribunales en busca de canalizar sus demandas por vía judicial. Sean asociaciones vecinales que se oponen a la construcción de pasos bajo nivel, movimientos ambientalistas que se proponen prohibir la fumigación con determinados agroquímicos, o colectivos LGBT que intentan que se reconozca la figura penal del travesticidio, se trata en todos los casos de una búsqueda de conquistar reivindicaciones - directa o indirectamente- por medio del uso de herramientas jurídicas. Pero la vía judicial no es necesariamente la única escogida por los demandantes: formas de reclamo como campañas públicas, movilizaciones u otros modos de acción directa suelen precederla o incluso acompañarla. Llegado este punto, el ingreso a los entramados del Poder Judicial no sólo implica un desplazamiento en los términos de tratamiento del conflicto sino que, incluso, puede tener como correlato cambios en los marcos de percepción y los horizontes de expectativas.

\section{JUECES, DEFENSORES Y PROCESOS POLÍTICOS: LOS ALCANCES DEL ACTIVISMO JUDICIAL}

Si la judicialización remite al traslado de diversas demandas y conflictos sociales al ámbito del Poder Judicial, no puede soslayarse la relevancia que reviste este fenómeno desde el punto de vista de los operadores jurídicos. Algunos autores se han referido a las variadas facetas de la 
expansión de la justicia como "activismo judicial" (DELAMATA, 2013; AZUELA, 2014; MARTIN, 2011) para dar cuenta de cómo determinados actores -sobre todo integrantes de esta rama del Estadotrascienden la ortodoxia del campo del derecho en pos de alcanzar objetivos entendidos como ajenos al ejercicio de la justicia.

Así, el activismo judicial refiere por un lado al accionar de abogados autónomos, de organizaciones no gubernamentales o de organismos de defensa pública que reclaman a la justicia por la violación de derechos y buscan generalizar su cumplimiento. Consiste, en otros términos, en el uso de estrategias legales para alcanzar objetivos políticos y sociales (SMULOVITZ, 2008), en general ligados a la defensa de los recientemente consagrados derechos económicos, sociales y culturales de población vulnerable, organizaciones populares y movimientos sociales.

La literatura ha caracterizado a estos actores como abogados "alternativos" (MANZO, 2016), "populares" (CARLET, 2015) o "anfibios" (AUTOR, 2019), debido a cómo llevan a cabo un "uso estratégico" o "contra hegemónico" del derecho con el fin de alcanzar objetivos políticos. En cualquier caso, se los concibe como operadores jurídicos que "humanizan al cliente", "politizan la demanda jurídica”, "crean estrategias de lucha” y "animan a la organización colectiva de la clientela" (MANZO, 2016). En otras palabras, consiste en prácticas que unen la expertise jurídica con el compromiso militante a favor de determinadas causas colectivas que implican la defensa de los derechos humanos (CARLET, 2015: 379). Trabajos de este tipo han demostrado en esta clave cómo el derecho, aunque para las teorías dominantes es un sistema de normas autónomo, coherente, neutral y ajeno a lo político, abre un campo tenso y a la vez productivo cuando lo utilizan “estratégicamente" actores sociales en lucha (VILLEGAS GUZMÁN, 2016: 124).

Claro está, estos usos del derecho difícilmente podrían circunscribirse a los sujetos que lo ponen en práctica. Más bien, merece destacarse cómo distintas instituciones -en particular las defensorías públicas- han dado cuenta de una especial predisposición a involucrarse en la defensa de los derechos consagrados en la nueva Constitución, adoptando como tarea garantizar el acceso a la justicia por medio del trabajo territorial (CHELLILLO et al., 2014).

Tal es el caso del Ministerio Público de la Defensa de la Ciudad de Buenos Aires, que se aboca a designar abogados a personas con escasos recursos económicos en conflicto con el Gobierno de la Ciudad de Buenos Aires. Desde su conformación, este organismo ha hecho particular hincapié institucional en la problemática de los habitantes de pensiones, villas y asentamientos, basándose en un discurso político-jurídico de defensa del "derecho a la ciudad" que afirma que "sin 
justicia social urbana no hay ciudadanía" (DEFENSORÍA GENERAL DE LA CIUDAD, 2016). Aquí, el activismo judicial de este organismo no refiere sino a la disputa jurídica por transformar el carácter programático de estos derechos en operativo ${ }^{5}$. Se trata, en otras palabras, del problema de la exigibilidad de los derechos fundamentales, es decir, de cómo los actores -y por medio de qué recursos y estrategias- organizan sus demandas en pos del cumplimiento de derechos vulnerados.

Por otro lado, el activismo judicial hace referencia a la politización de los jueces y tribunales. Pero no es el eje de atención aquí si ello se traduce en un alineamiento más o menos explícito de estos actores con determinados sectores políticos. Más bien, el interés está en cómo los límites de lo justiciable se expanden hacia terrenos habitualmente reservados a formas no judiciales de tramitación de los conflictos, acrecentándose la capacidad de la justicia de torcer el rumbo de éstos y en particular de generar cambios en las agendas pública y gubernamental por medio del involucramiento en la definición de políticas públicas.

Como indica Abramovich (2005), son cada vez más numerosas las causas en las que los jueces colocan determinadas políticas públicas bajo su tutela, involucrándose no sólo en su evaluación sino también en su diseño e inclusive en su ejecución. Este aspecto de la judicialización es acaso uno de los que más controversia despierta en el debate público y entre las instituciones estatales, pues supone el avance de los tribunales sobre lo que con frecuencia se entiende como uno de los atributos del ejercicio del gobierno por excelencia de acuerdo a la concepción montesquevina de la división de poderes -según la cual al Poder Legislativo le concerniría la formulación de leyes, al Poder Judicial el ejercicio de la justicia, y al Poder Ejecutivo la implementación de políticas-. Más aún, la judicialización en materia de políticas públicas pone de relieve que se trata de un fenómeno que no consiste meramente en el ingreso de los conflictos al mundo de los tribunales -donde, tras traducirse a términos jurídicos, aquellos se clausurarían- sino que comprende también a los procesos por los que en el seno de la justicia se construyen "soluciones" que, al traducirse posteriormente a términos políticos, se convierten en conflictos.

\footnotetext{
${ }^{5}$ Analizar la exigibilidad de los derechos supone indefectiblemente examinar de qué modo para los actores vulnerados tales derechos se vuelven justiciables. En otras palabras, se vuelve un asunto primordial cómo el Poder Judicial se torna una puerta de entrada para las demandas sociales. La noción de "acceso a la justicia", a partir de la cual la literatura a menudo ha abordado este problema (DE STEFANO, 2012, entre otros), permite indagar en cómo las garantías, instituciones y procedimientos habilitados por los entramados jurídicos entran en acción para allanar un canal de reclamo en los tribunales, especialmente por parte de los sectores de menores recursos, es decir, aquellos cuyos derechos fundamentales suelen ser los más vulnerados y cuyas posibilidades objetivas de plantear una demanda judicial tienden a ser menores.
} 
Merecen mención en este sentido las decisiones judiciales activistas que pretenden generar cambios culturales extendidos, atención social en torno a determinado tema, transformaciones institucionales o alteraciones en las correlaciones de fuerza entre actores políticos. Pueden traerse a colación los pedidos de prisión preventiva a dirigentes políticos en Argentina o bien la declaración de constitucionalidad del matrimonio entre personas del mismo sexo en Estados Unidos, pero también la nueva generación de "casos estructurales" que conminan a múltiples agencias estatales a buscar soluciones duraderas a la vulneración masiva de derechos, como la "causa Verbitsky", en la cual la Corte Suprema de Argentina requirió la reforma del sistema carcelario (PUGA, 2013: 44), la sentencia T-025, con la cual la justicia colombiana buscó solucionar la situación de los desplazados por el conflicto armado (RODRíGUEZ GARAVITO Y RODRÍGUEZ FRANCO, 2015), o la "causa Riachuelo", que apuntó a generar una respuesta integral a la degradación ambiental de una cuenca hidrográfica en Buenos Aires (MERLINSKY, 2013).

A diferencia del litigio tradicional (que plantea un conflicto de derechos limitado al demandante y el demandado), el litigio "estratégico" o "estructural" expande el territorio de lo justiciable más allá de los intereses de las partes procesales (PUGA, 2013: 46) y pone en la escena jurídica objetivos colectivos y de largo plazo que acaban por involucrar a la estructura y funcionamiento de determinadas instituciones estatales. De este modo -siguiendo a Martin (2011), además de remediar determinado derecho dañado, suele generar reconocimiento social y legitimidad política en torno a una problemática.

\section{HACIA UNA SOCIOLOGÍA DE LA JUDICIALIZACIÓN}

\section{La dimensión simbólica del derecho}

Según Antonio Azuela (2006), la judicialización debe distinguirse conceptualmente de la juridificación. En tanto aquella remitiría a los mecanismos y procedimientos de la justicia, ésta permitiría referirse a los modos en que la sociedad se transforma cuando las expectativas y horizontes de acción de los actores se adecúan a las reglas del mundo jurídico.

Esta observación resulta de suma importancia para un análisis sociológico de los efectos de la judicialización, ya que abre las puertas a la adopción de una perspectiva multidimensional sobre el derecho: éste ya no se reduciría a un entramado normativo, sino que se lo podría entender como un lenguaje o cosmovisión que otorga determinados marcos cognitivos para definir las situaciones. 
Es decir que si efectivamente es posible hacer cosas con palabras y el discurso cuenta con un poder performativo (AUSTIN, 1975), entonces el derecho no sólo tiene la capacidad de designar la realidad sino también de conformarla. Más aún, como vimos con el caso de la construcción de torres en un barrio de Buenos Aires -que fue legalmente encuadrado como afectación al medioambiente-, puede incluso contribuir al desplazamiento de un conflicto de un campo de demandas a otro. Por ende, a la vez que cuenta con una función regulatoria, el derecho posee una función simbólica; es un "sistema de acción" y simultáneamente un "sistema de conocimiento" (HABERMAS, 1998: 79, en AZUELA, 2006) capaz de construir categorías y modos de percepción.

Como apunta Azuela, a partir del "giro lingüístico" las ciencias sociales hallaron en el lenguaje no únicamente una capacidad de referirse al mundo social sino también de instituirlo. En función de este punto de partida, se habilita la concepción de los fenómenos jurídicos no sólo como normas reguladoras de conductas sino, esencialmente, como discursos que se incorporan a los marcos de entendimiento, pensamiento y acción de los actores (BOURDIEU, 1986). Ahora bien, esto no significa, según Azuela, que el derecho "cree" a la sociedad, pero sí que hace las veces de vehículo mediante el cual se impone una manera de definirla.

Analizar la judicialización en relación a su dimensión simbólica, por lo tanto, supone asumir que las sentencias y procesos judiciales, además de tener consecuencias de orden material, generan transformaciones indirectas en los vínculos sociales, en las representaciones de los actores y por ende en las estrategias que éstos se dan ante lo que está en disputa (MELÉ, 2011). Más aún, pueden cambiar todo el marco de tratamiento de un problema público y hacer decible algo previamente inenunciable (RODRÍGUEZ GARAVITO, 2011), como el "derecho al ambiente" o el "derecho a la ciudad", es decir, significantes con la capacidad de volverse símbolos maestros que estructuran las dinámicas de los conflictos (SHORE, 2010).

Esta perspectiva requiere la adopción de una visión constructivista de la relación entre derecho y sociedad (BOURDIEU, 1986), de modo tal de evitar una concepción de la judicialización en términos patológicos -como si fuera producto de una desviación política o jurídica respecto del funcionamiento normal (o deseable) del Estado y las instituciones- y asimismo trascender el normativismo -que se pregunta qué tan positiva o negativa resulta la expansión de los terrenos de la justicia para la democracia, el ejercicio del gobierno o la ciudadanía (O'DONNELL, 2008)-. Como indica Rodríguez Garavito (2011), la tarea no sólo es focalizarse en los efectos materiales y directos de las decisiones de la justicia, sino atender a cómo éstas generan transformación social cuando 
conllevan cambios de conducta, alteran las relaciones sociales o modifican las percepciones de los actores legitimando las cosmovisiones de los litigantes. De adoptarse este punto de vista, se debe asumir entonces que los conflictos sobre los cuales la justicia interviene no son expresión de una crisis o disfuncionalidad social que requiere reencauzarse, sino instancias estructurantes y generadoras de nuevos órdenes, es decir, momentos de constitución de lazos y producción de transformaciones sociales duraderas. Por lo tanto, al permear el desenvolvimiento de la conflictividad, la judicialización engendra efectos de largo alcance que pueden oscilar desde lo político y lo institucional hasta lo distributivo y lo simbólico.

\section{La topografía imaginaria de los procesos judiciales}

Una sociología de los procesos de judicialización requiere, asimismo, evitar la reificación del derecho y el Poder Judicial, como si fuesen unívocos y estuviesen escindidos de la sociedad. En otras palabras, debe evitarse analizar las sentencias judiciales activistas en tanto procesos de decision making (MITCHELL, 1999), como si las instituciones de la justicia se ubicaran encima o fuera de la sociedad, orientadas por una "racionalidad superior" (O'DONNELL, 1978: 18). Parafraseando a Ferguson (2007), esta perspectiva sólo abona al sostenimiento de una topografía imaginaria según la cual las disputas políticas vienen "desde abajo" y la justicia se hace "desde arriba".

En esta clave, en parte de la literatura se dejan entrever concepciones sobre la naturaleza estatal que en términos teóricos obturan más de lo que potencian el análisis de la productividad de la judicialización. Es el caso de trabajos que afirman que cuando la judicialización es impulsada por actores políticos o judiciales tiene un origen "desde arriba" y cuando es estimulada por "sectores de la sociedad" su origen se ubica "abajo" (SIEDER, SCHJOLDEN Y ANGELL, 2008: 4, traducción propia).

Pero si el sistema de poder -como afirma Foucault-se extiende mucho más allá del Estado (MITCHELL, 1999), ¿ ¿cómo se definen los límites del aparato estatal? ¿Dónde se halla el adentro y el afuera? Unidas en los imaginarios populares y los discursos académicos (FERGUSON, 2007), estas ideas dificultan la posibilidad de comprender las características, los efectos y los alcances de la judicialización, no sólo porque perpetúan la escisión de lo social respecto de lo judicial sino porque conducen a analizar las consecuencias de la judicialización de acuerdo a una lógica "top down". Superar este meollo teórico requeriría observar la judicialización más bien como un proceso "a 
través", para así rastrear los modos en que se crean redes y relaciones entre actores, instituciones y discursos (SHORE Y WRIGHT, 1997).

El derecho, tal como señala Mitchell (1999), es un ejemplo de este problema: el sistema legal consiste en un complejo sistema que, al abarcar desde estatutos, agencias penales y códigos hasta psiquiatras, universidades y círculos académicos, dificulta hallar una línea divisoria exacta entre la estructura legal y la sociedad. En la práctica se tiende a pensar en el derecho como un código abstracto y a la sociedad como el reino de su aplicación práctica, pero en los hechos, el código y la práctica tienden a ser aspectos inseparables.

Por estos motivos, es preciso apegarse a los actores en situación, sus solapamientos y sus mecanismos de coordinación, desabroquelando los procesos judiciales y dando cuenta de su producción y transformación en términos interactivos. En efecto, debe asumirse que, lejos de ser estáticas, las definiciones que la justicia construye acerca de los problemas se alteran de modo continuo, por lo cual una sociología de la judicialización debe analizar las sentencias no como punto de fuga en el cual converge -para clausurarse- un proceso previo de definición, sino como prisma que captura un asunto de interés social -o bien sencillamente lo crea- para luego relanzarlo bajo nuevas formas. Por ende, lejos de culminar en el fallo de un juez, la judicialización tiene una productividad multidimensional que genera efectos no deseados o incluso desconocidos para los propios actores. Claro está, el poder simbólico que ejerce la justicia permite que los fallos se presenten como solución, pero conforman instancias conflictivas en sí mismas pues reconfiguran los problemas al ponerlos en marcha bajo otras reglas de juego, reformulando o desplazando sus categorías.

\section{El estudio de la judicialización y las fronteras disciplinares}

Deben remarcarse, por último, una serie de desafíos que supone el abordaje de la judicialización desde las ciencias sociales. Por un lado, en la medida en que se trata de procesos de ampliación de la esfera de influencia de la justicia, se requiere indefectiblemente adentrarse en sus lógicas de funcionamiento intrínsecas. La comprensión de los códigos y significados que orientan a los actores integrantes del Poder Judicial es una deuda de la sociología en la Argentina, la cual ha tendido a rehuir a los entramados del derecho y cuenta con grandes déficits en la creación de conocimiento acerca de esta rama del Estado. 
Por otro lado, no obstante, el acercamiento al mundo de la justicia no está exento de riesgos. Como recuerdan Dezalay y Rask Madsen (2012), cualquier indagación sociológica sobre el derecho que se coloque demasiado cerca de su ortodoxia corre el riesgo de quedar atrapada en su lógica de dominación y verse así teñida por los vicios y limitaciones del pensamiento jurídico. Este es, en definitiva, el gran problema con la sociología del derecho (BOURDIEU, 1986), razón por la cual estudiar la judicialización desde las ciencias sociales implica hacer caso omiso a toda pretensión de exclusividad sobre el tema esgrimida por los juristas; es decir, requiere cuestionar y traspasar las fronteras disciplinarias que reservan el análisis de los problemas relativos a la justicia a quienes la practican o habitualmente se arrogan la potestad de cultivar saber sobre ella (NOSETTO, 2014).

En otras palabras, debe adoptarse una concepción del derecho más abierta, contextual y anclada en sus usos sociales. En lugar de analizarlo desde una posición interna -de acuerdo a su puesta en obra, su coherencia y sus fundamentos, como proponen juristas y filósofos del derecho, debe realizarse un estudio externo (MELÉ, 2011). Eventualmente, en vías de comprender la judicialización como fenómeno jurídico intrínseco podría bastar el saber que el derecho produce acerca de sí mismo, pero éste es insuficiente si se procura analizarla como fenómeno social. Su estudio implica entonces un desafío a delimitaciones preestablecidas que requiere el entrecruzamiento del mundo jurídico con la política, la historia y las ciencias sociales.

\section{CONCLUSIONES}

En la medida en que la justicia opera como reguladora de las relaciones sociales, la ampliación de su esfera de influencia hacia conflictos que otrora se tramitaran y saldaran por canales no judiciales es una problemática cuyos efectos alcanzan a la sociedad y al funcionamiento del Estado. Hemos visto en estas páginas que la judicialización debe entenderse como un creciente involucramiento del Poder Judicial en asuntos de la vida social y política y un desplazamiento de las instancias por las que los actores canalizan los conflictos, sea por iniciativa de los jueces o porque los propios actores lo consideran ventajoso. Dicho de otro modo, consiste en un vínculo novedoso entre la política -entendida como forma no judicial de tramitación de los conflictos- y la propia esfera judicial, que comienza a implicarse en problemas usualmente zanjados en otros campos y a volverse el ámbito donde ciertos actores sociales intentan acotar los márgenes de acción de otros; especialmente, fiscalizar o impugnar decisiones gubernamentales, así como dialogar o confrontar con sus diferentes instancias (DELAMATA, 2016). Esta presencia cada vez mayor de los tribunales en 
los horizontes de acción de los actores y en el derrotero de los conflictos mismos produce, en última instancia, una transformación en las relaciones entre los grupos sociales en disputa así como una transferencia de la toma de decisiones político-estatales de las legislaturas y los ministerios a las cortes y los juzgados (VALLINDER, 1994; ABDO FEREZ, 2013).

La judicialización, por lo tanto, debe entenderse como un proceso de creciente entrelazamiento de la justicia con los procesos políticos y sociales, que conlleva un uso cada vez más habitual del derecho y los mecanismos legales por parte de diversos actores que se movilizan en torno a determinados intereses, problemáticas o demandas. Así, se extiende la discusión en clave jurídica y se incrementa la invocación de los derechos en instancias tan variadas como manifestaciones populares, discursos de funcionarios y el quehacer de organizaciones de la sociedad civil (ARCIDIÁCONO Y GAMALLO, 2014). Sobre todo, el derecho se fortalece como marco interpretativo de los actores (DELAMATA, 2013), es decir, como brújula con la cual se conducen ante la conflictividad. Siguiendo el concepto de Tilly (2008), podría afirmarse que la judicialización coloca a la apelación a la justicia en un lugar cada vez más relevante dentro de los repertorios de protesta social. Los cambios en las posibilidades objetivas para emplazar demandas, junto con el fortalecimiento social del derecho, tienden a que la acción directa se vea complementada (y en algunos casos reemplazada) por la acción en los tribunales.

Asimismo, debe concebirse a la judicialización como fenómeno cuyos efectos sobre la producción de políticas y las relaciones sociales son tanto materiales como simbólicos. En otras palabras, además de evidenciar una influencia decisiva en los modos en que se elaboran los planes y programas estatales y se desarrollan los conflictos, puede incluso generar cambios en los horizontes de inteligibilidad de los actores. En definitiva, debe habilitarse un análisis multidimensional del desarrollo y los efectos de los procesos de judicialización, entendido como fenómeno de profundas implicancias políticas y sociales en Argentina y América Latina.

\section{NOTAS}

\section{REFERENCIAS BIBLIOGRÁFICAS}

ABDO FEREZ, Cecilia. La política y la juristocracia. En Revista Sociedad, no 33, 2013, pp. 51-72. 
ABRAMOVICH, Víctor. Acceso a la justicia y nuevas formas de participación en la esfera política. En Estudios socio-jurídicos, no 9, 2005, pp. 9-33.

ARCIDIÁCONO, Pilar; GAMALLO, Gustavo. Entre la confrontación y la funcionalidad: Poder Ejecutivo y Poder Judicial en torno a la política habitacional de la ciudad de Buenos Aires. En PAUTASSI, Laura. (dir.). Marginaciones sociales en el Área Metropolitana de Buenos Aires. Acceso a la justicia, capacidades estatales y movilización legal. Buenos Aires: Biblos, 2014.

ARRIMADA, Lucas. Las 10 razones para judicializar la política. En Diario Perfil, 2017. Disponible en: https://www.perfil.com/noticias/politica/las-10-razones-para-judicializar-la-politica.phtml. Acceso: 12/05/19.

AUSTIN, John Langshaw. How to do things with words. Cambridge: Harvard University Press, 1975.

AUTOR (2019)

AXAT, Julián et al. La judicialización de la protesta social. En MORAS et al. La criminalización de la protesta social. La Plata: La Grieta Ediciones, 2003.

AZUELA, Antonio. Visionarios y pragmáticos. Una aproximación sociológica al derecho ambiental. México: Instituto de Investigaciones Sociales (UNAM) y Editorial Fontamara, 2006.

AZUELA, Antonio. Introducción. En AZUELA, Antonio; CANCINO, Miguel Ángel (eds.). Jueces y conflictos urbanos en América Latina. México: PAOT-IRGLUS, 2014.

AZUELA, Antonio; COSACOV, Natalia. Transformaciones urbanas y reivindicaciones ambientales: en torno a la productividad social del conflicto por la construcción de edificios en la Ciudad de Buenos Aires. En EURE (Santiago), 39(118), 2013, pp. 149-172.

BIEHL, Joao; AMON, Joseph; SOCAL, Mariana; PETRYNA, Adriana. Between the court and the clinic: lawsuits for medicines and the right to health in Brazil. En Health Human Rights, 14(1), 2012, pp. 36-52.

BOURDIEU, Pierre. The force of law: Toward a sociology of the juridical field. En Hastings $L, 38$, 805, 1986.

BRINKS, Daniel ; GAURI, Varun. The law's majestic equality? The distributive impact of judicializing social and economic rights. En Perspectives on Politics, 12(2), 2014, pp. 375-393.

CARBONELL, Miguel (ed.). Teoría del neoconstitucionalismo. Ensayos escogidos. Madrid: TrottaUNAM, 2007.

CARDINAUX, Nancy; CLÉRICO, Laura; ALDAO, Martín; RONCONI, Liliana. Hacia la reconstrucción de un perfil de juez/a permeables a las demandas de identidad de género: el caso del contencioso administrativo tributario de la ciudad de Buenos Aires. En Ambiente jurídico, (14), 2012, pp. 16 35.

CARLET, Flávia. Advocacia Popular: práticas jurídicas contra-hegemônicas no acesso ao direito e à justiça no Brasil. En Revista Direito E Práxis, vol. 6, № 10, 2015. 
CHELLILLO, Mauro. et al. El "qué". Las relocalizaciones en el marco de la causa Riachuelo y el derecho a la ciudad. En Revista Institucional de la Defensa Pública de la Ciudad Autónoma de Buenos Aires, año 4, no 6, 2014, pp. 23-40.

CONAGHAN, Catherine. Prosecuting presidents: The politics within Ecuador's corruption cases. En Journal of Latin American Studies, 44(4), 2012, pp. 649-678.

DE STEFANO, Juan Sebastián. Acceso a la justicia. Análisis y perspectivas de los nuevos desafíos. Buenos Aires: Eudeba, 2012.

DEFENSORÍA GENERAL DE LA CIUDAD. Revista Institucional de la Defensa Pública de la Ciudad Autónoma de Buenos Aires, año 6, no 10, 2016.

DELAMATA, Gabriela. Amanecer y progreso de un repertorio social activista de derechos bajo la democracia recuperada. En Revista SAAP, vol. 7, no 2, 2013, pp. 307-315.

DELAMATA, Gabriela. Una década de activismo judicial en las villas de Buenos Aires. En Revista Direito e Práxis, 7(14), 2016.

DEZALAY, Yves; RASK MADSEN, Mikael. The force of law and lawyers: Pierre Bourdieu and the reflexive sociology of law". En Annual review of law and social science, no 8, 2012, pp. 433-452.

DOMINGO, Pilar. Judicialization of politics or politicization of the judiciary?. En Recent trends in Latin America, Democratization, 11:1, 2004, pp. 104-126.

EDELMAN, Martin. The judicialization of politics in Israel. En International Political Science Review, 15(2), 1994, pp. 177-186.

FEDERACIÓN ARGENTINA LGBT. Matrimonio para todas y todos. El largo camino a la igualdad. S/F. Disponible en http://www.lgbt.org.ar/blog/Matrimonio/matrimonio.htm. Acceso: $14 / 12 / 2018$.

FERGUSON, James. Power topographies. En NUGENT, David; VINCENT, Joan (eds.). A companion to the anthropology of politics, Blackwell Publishing: Londres. 2007.

FINKEL, Jodi. Judicial Reform as Insurance Policy: Mexico in the 1990s. En Latin American Politics and Society, 47 (1), 2005, pp. 87-113.

GALANTE, Diego. Memorias de la violencia política y sintaxis judicial: para una tipología del sujeto de derecho en la Argentina de los ochenta. Ponencia presentada en las VI Jornadas de Jóvenes Investigadores del Instituto de Investigaciones Gino Germani. Facultad de Ciencias Sociales, Universidad de Buenos Aires, 2011.

GARGARELLA, Roberto. ¿Democracia deliberativa y judicialización de los derechos sociales? En Perfiles latinoamericanos, no 8, 2006, pp. 9-32.

HABERMAS, Jürgen. Between facts and norms. Cambridge: The MIT Press, 1998.

$\mathrm{HE}, \mathrm{Xin}$. Judicial innovation and local politics: Judicialization of administrative governance in East China. En The China Journal, no 69, 2013, pp. 20-42. 
HILBINK, Lisa. An exception to Chilean exceptionalism? En ECKSTEIN, Susan; WICKHAM CRAWLEY, Timothy (eds.) What Justice? Whose Justice? Fighting for Fairness in Latin America.

Berkeley: University of California Press, 2003.

HIRSCHL, Ran. "Juristocracy". Political, not Juridical. En The Good Society, 13(3), 2004, pp. 6-11.

KALUSZYNSKI, Martine. La judiciarisation de la société et du politique. Ponencia presentada en Face à la judiciarisation de la société, les réponses de la Protection Juridique. Paris, Francia, 2006.

KAPISZEWSKI, Diana; TAYLOR, Matthew. Doing courts justice? Studying judicial politics in Latin America. En Perspectives on politics, 6(4), 2008, pp. 741-767.

KATZ, Claudio. Desenlace del ciclo progresista. En Estudios críticos del desarrollo, vol. VII, no 12, 2017, pp. 87-122.

KONZEN, Lucas. Conflictos urbanos y activismo judicial en Brasil: el caso Pinheirnho. En AZUELA, Antonio; CANCINO, Miguel Ángel (coords.) Jueces y conflictos urbanos en América Latina. México: PAOT-IRGLUS, 2014.

MANZO, Mariana. Identidades profesionales: El lugar que ocupa el derecho y la política en el ejercicio profesional de los abogados activistas en Argentina. En Revista Direito e Práxis, vol. 7, no 15, 2016, pp. 175-212.

MARTíN, Lucas. Giro judicial y legitimidad pública en la política argentina. En CHERESKY, I. (ed) Ciudadanía y legitimidad democrática en América Latina, Buenos Aires: Prometeo, 2011.

MELE, Patrice. Actualisation locale du droit. Ponencia presentada en Séminaire Géographie et droit, géographie du droit. Carcasonne: UMR-PRODIG, 2011

MERLINSKY, Gabriela. Política y justicia ambiental en la metrópolis de Buenos Aires. El conflicto del Riachuelo. Buenos Aires: Fondo de Cultura Económica, 2013.

MITCHELL, Timothy. Society, economy, and the State effect. En G. STEINMETZ (ed.) State/culture: State-formation after the cultural turn, Ithaca, NY: Cornell University Press, 1999, pp. 76-97.

NOSETTO, Luciano. Reflexiones teóricas sobre la judicialización de la política argentina. En Documentos y aportes en administración pública y gestión estatal, no 23, 2014.

O’DONNELL, Guillermo. Apuntes para una teoría del Estado. En Revista Mexicana de Sociología, vol. 40, no 4, 1978, pp. 1157-1199.

O’DONNELL, Guillermo. Algunas reflexiones acerca de la democracia, el Estado y sus múltiples caras. En Revista del CLAD - Reforma y democracia, no 42, 2008, pp. 5-30.

PEÑAS DEFAGO, María Angélica; MORÁN FAÚNDES, José Manuel. Conservative litigation against sexual and reproductive health policies in Argentina. En Reproductive Health Matters, 22(44), 2014, pp. 82-90. 
PÉREZ PERDOMO, Rogelio. Judicialization and regime transformation: The Venezuelan Supreme Court. En SIEDER, Rachel; SCHJOLDEN, Line; ANGELL, Alan (eds.) The Judicialization of Politics in Latin America. Nueva York: Palgrave Macmillan, 2005.

PUGA, Mariela. El litigio estructural. En Revista de Teoría del Derecho de la Universidad de Palermo, 2013, pp. 41-82.

RODRÍGUEZ GARAVITO, Carlos. Beyond the courtroom: the impact of judicial activism on socioeconomic rights in Latin America. En Texas Law Review, no 7, vol. 89, 2011, pp. 16-69.

RODRÍGUEZ GARAVITO, César; RODRÍGUEZ FRANCO, Diana. Juicio a la exclusión. El impacto de los tribunales sobre los derechos sociales en el Sur Global. Buenos Aires: Siglo Veintiuno Editores, 2015.

SANTIAGO, Alfonso. Neoconstitucionalismo. En Anales Academia Nacional de Ciencias Morales y Políticas, 35, 2008.

SANTISO, Carlos. Economic reform and judicial governance in Brazil: Balancing independence with accountability. En Democratization and the Judiciary: The Accountability Function of Courts. Londres: Frank Cass Publishers, 2004.

SANTOS, Boaventura de Sousa. Sociología Jurídica Crítica. Para un nuevo sentido común en el derecho. Madrid: Trotta/ILSA, 2009.

SHAPIRO, Martin. Judicialization of Politics in the United States. En International Political Science Review / Revue Internationale De Science Politique, 15(2), 1994, pp. 101-112.

SHORE, Cris. La antropología y el estudio de la política pública: reflexiones sobre la 'formulación' de las políticas. En Antípoda, n¹0, 2010, pp. 21-49.

SHORE, Cris; WRIGHT, Susan. Policy: a new field of anthropology, en Anthropology of policy. Critical perspectives on governance and power, 1997, pp. 3-39.

SIEDER, Rachel; SCHJOLDEN, Line; ANGELL, Alan (eds.). La judicialización de la política en América Latina. Bogotá: Universidad Externado de Colombia, 2008.

SMULOVITZ, Catalina. La política por otros medios. Judicialización y movilización legal en la Argentina. En Desarrollo Económico, vol. 48, n 189-190, 2008.

TATE, Neal. The judicialization of politics in the Philippines and Southeast Asia. En International Political Science Review, 15(2), 1994, pp. 187-197.

TILLY, Charles. Contentious performances. Cambridge: Cambridge University Press, 2008.

VALLINDER, Torbjorn. The judicialization of politics. A World-wide Phenomenon: Introduction, 1994.

VILLEGAS GUZMÁN, Sabrina. Una propuesta teórica para el análisis entre Derecho y luchas sociales. En Revista Argumentos, no 2, 2016, pp. 122-138.. 
Trabalho enviado em 09 de dezembro de 2019

Aceito em 30 de janeiro de 2020 